\title{
Mechanisms of atherothrombosis in chronic obstructive pulmonary disease
}

\author{
Filippo Luca Fimognari ${ }^{1,2}$ \\ Simone Scarlata' \\ Maria Elisabetta Conte' \\ Raffaele Antonelli Incalzi' \\ 'Health Centre for Elderly, Chair \\ of Geriatrics, University Campus \\ Bio Medico, Rome, Italy; ${ }^{2}$ Internal \\ Medicine; ASL Roma G, Leopoldo \\ Parodi-Delfino Hospital; Colleferro, \\ Rome, Italy
}

\begin{abstract}
Patients affected by chronic obstructive pulmonary disease (COPD) have an increased risk of atherothrombotic acute events, independent of smoking and other cardiovascular risk factors. As a consequence, myocardial ischemia is a relevant cause of death in these patients. We reviewed studies concerning the potential mechanisms of atherothrombosis in COPD. Bronchial inflammation spreads to the systemic circulation and is known to play a key role in plaque formation and rupture. In fact, C-reactive protein blood levels increase in COPD and provide independent prognostic information. Systemic inflammation is the first cause of the hypercoagulable state commonly observed in COPD. Furthermore, hypoxia is supposed to activate platelets, thus accounting for the increased urinary excretion of platelet-derived thromboxane in COPD. The potential metabolic risk in COPD is still debated, in that recent studies do not support an association between COPD and diabetes mellitus. Finally, oxidative stress contributes to the pathogenesis of COPD and may promote oxidation of low-density-lipoproteins with foam cells formation. Retrospective observations suggest that inhaled corticosteroids may reduce atherothrombotic mortality by attenuating systemic inflammation, but this benefit needs confirmation in ongoing randomized controlled trials. Physicians approaching COPD patients should always be aware of the systemic vascular implications of this disease.
\end{abstract}

Keywords: COPD, atherothrombosis, cardiovascular risk, mortality

\section{Introduction}

Chronic obstructive pulmonary disease (COPD) is a leading cause of death worldwide (Calverley and Walker 2003). In addition to the healthcare costs, COPD imposes a significant burden in terms of disability and impaired quality of life. Unlike many other leading causes of death and disability, COPD prevalence will raise in the majority of countries as smoking frequency increases and the population ages (Halbert et al 2006). The World Health Organization predicts that by 2020 COPD will be the 5 th most prevalent disease worldwide (presently the 12th) and the 3th most common cause of death (presently the 6th). Not respiratory outnumber respiratory causes of death, and most of them are cardiovascular causes (Hansell et al 2003). This is the rationale for reviewing the main mechanisms of the COPD-related atherothrombotic risk.

We performed a series of MEDLINE database searches for English language literature published from 1970 to April 2007 by combining the medical subject heading $(\mathrm{MeSH})$ terms chronic obstructive pulmonary disease, chronic bronchitis and pulmonary emphysema with the following MeSH terms atherosclerosis, thrombosis, platelet activation, platelet aggregation, thromboxane, inflammation, inflammation mediators, C-reactive protein, blood coagulation, blood coagulation mediators, blood coagulation factor inhibitors, corticosteroids, catecholamines, sympathetic nervous system, oxidative stress, isoprostanes, F2 isoprostanes. We also supplemented references by cross-checking bibliographies of retrieved articles to identify additional studies. 


\section{COPD and atherothrombotic risk: the epidemiological evidence}

Reduced forced expiratory volume in 1 second $\left(\mathrm{FEV}_{1}\right)$ was associated with increased pulse wave velocity, a surrogate measurement for central arterial stiffness, endothelial dysfunction and atherosclerosis (Zureik et al 2001).

Although not generally recognized, a low $\mathrm{FEV}_{1}$, has been shown to be as powerful a predictor of cardiac mortality as total serum cholesterol, irrespective of the effect of smoking and other possible confounders (Hole et al 1996). In a recent meta-analysis (Sin et al 2005b), the relative risk of cardiovascular death in the group with the lowest $\mathrm{FEV}_{1}$ compared with that with the highest $\mathrm{FEV}_{1}$ was 3.36 (1.54-7.34); the corresponding figure for mortality due to myocardial ischemia was 5.65 (2.26-14.13). As a consequence, coronary artery disease is one of the leading causes of death in COPD patients (Hansell et al 2003).

$\mathrm{FEV}_{1}$ /forced vital capacity $\left(\mathrm{FEV}_{1} / \mathrm{FVC}\right)$ ratio, a more sensitive parameter of obstructive disease than $\mathrm{FEV}_{1}$, was also found to be independently related to vascular events (Engstrom et al 2001).

The overall atherothrombotic impact of COPD is further proved by the increased risk of ischemic stroke in COPD patients. In a 15-year follow up, the relative risk of fatal stroke was $1.1(1.03-1.2)$ for every $10 \%$ decrease of $\mathrm{FEV}_{1}$ (Truelsen et al 2001).

\section{Pro-atherothrombotic mechanisms in COPD}

The mechanisms responsible for the association between COPD and atherothrombosis are still largely unknown. However, at least four factors seem to be pathogenetically important: chronic systemic inflammation, hypercoagulable state, platelet activation and oxidative stress (Figure 1).

\section{Systemic inflammation (Table I)}

In the context of the complex and multifactorial pathogenesis of atherothrombosis, low grade systemic inflammation is believed to be a crucial mechanism in plaque formation and rupture (Pasceri et al 2000). This concept is strongly supported by experiments showing that some inflammatory markers, such as C-reactive protein (CRP) and fibrinogen, are implicated in plaque formation. CPR upregulates the production of pro-inflammatory cytokines and tissue factor by monocytes, increases the uptake of low-density lipoproteins (LDL) by macrophages with foam cells formation and directly induces expression of adhesion molecules by human endothelial cells (Pasceri et al 2000).
Alveolar macrophages, bronchial epithelial cells and lymphocytes, which are implicated in bronchial and alveolar inflammation, produce interleukin (IL)-6 and IL-1 $\beta$. These cytokines, besides inducing local pro-inflammatory changes, "spill-over" into the systemic circulation and stimulate hepatocytes to synthesize CRP and fibrinogen. Accordingly, systemic blood concentrations of tumor necrosis factor (TNF)- $\alpha$, IL 6, IL 8, CRP and fibrinogen are higher in COPD than in control subjects (Gan et al 2004). Interestingly, at variance from the response observed in healthy subjects and diabetic patients, moderate-intensity exercise abnormally increases plasma TNF- $\alpha$ levels in COPD patients (Rabinovich et al 2003; Zoppini et al 2006). Circulating TNF- $\alpha$ levels have been found to increase in malnourished COPD patients, likely because systemic hypoxia stimulates TNF- $\alpha$ synthesis (Takabatake et al 2000). TNF- $\alpha$ can cause the expression of tissue factor on monocytes and, possibly, endothelium, thereby initiating the coagulation cascade (Esmon 2000).

CRP serum levels have also been found to increase for increasing severity of bronchial obstruction, ie, in COPD, the level of "systemic" inflammation (CRP) strictly parallels that of "local" bronchial inflammation and obstruction $\left(\mathrm{FEV}_{1}\right)$ (Sin and Man 2003). In addition, COPD patients with high CRP serum levels have increased risk of either atherothrombotic events (fatal and nonfatal coronary artery disease and stroke) or all-cause mortality, after adjusting for age, sex, smoking and lung function (Man et al 2006). These recent data support the role of the systemic inflammation in the development of atherothrombotic disorders in COPD. In addition, they suggest that CRP measurements should be considered in prognostic models for COPD patients.

Pulmonary hypertension is highly prevalent also in nonhypoxemic COPD and predicts a poor prognosis (Weitzenblum et al 1981). In a recent study, CRP and hypoxia were the only significant correlates of systolic pulmonary arterial pressure, suggesting that systemic inflammation may be involved in the pathogenesis of COPD-related pulmonary hypertension (Joppa et al 2006).

\section{Hypercoagulable state (Table 2)}

Some case-control studies have clearly established that, independent of current smoking, plasma levels of fibrinogen and other markers of coagulation are significantly higher in stable COPD patients than in healthy subjects (Alessandri et al 1994; Xie and Wang 1998; Wedzicha et al 2000; Ashitani et al 2002). The increased procoagulant activity in COPD may primarily result from inflammation. In fact, inflammation can trigger coagulation by promoting tissue-factor gene 


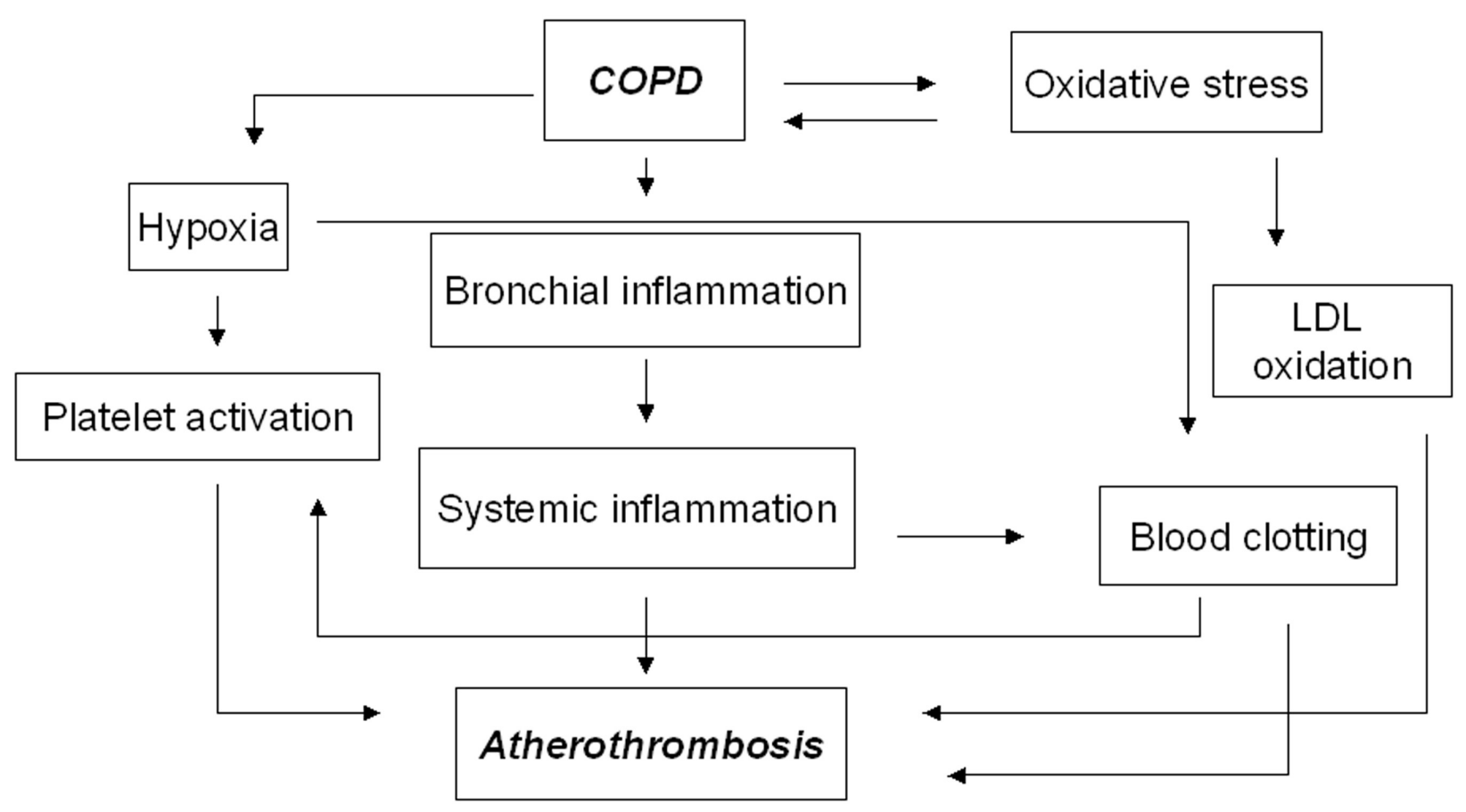

Figure I The COPD-atherothrombosis network.

expression in endothelial cells (Esmon 2000; Libby 2001). Hypoxia also could either reduce endothelial thrombomodulin expression or activate factor X (Ogawa et al 1990). Coagulation, in turn, amplifies inflammation and both are strongly implicated in the pathogenesis of atherothrombosis (Libby and Simon 2001). That a pro-coagulant status may promote atherothrombosis in COPD is suggested by the direct relationship between serum fibrinogen and the incidence of cardiovascular events in the general population (Danesh et al 1998). Interestingly, central pulmonary lesions, indicative of in situ thrombosis and atherosclerosis, are common in stable COPD patients even free from pulmonary hypertension, and their extent is not strictly related to the severity of bronchial obstruction (Russo et al 1999). This finding testifies to a procoagulant and proatherosclerotic status which can be recognized early in the course of COPD.

Importantly, fibrinogen levels rise further during COPD exacerbation (Wedzicha et al 2000). The acute release of this and other prothrombotic factors may thus account for the increased rate of myocardial infarctions immediately following low-respiratory tract infections (Meier et al 1998).

\section{Platelet activation (Table 3)}

The role of platelet in atherothrombosis is clearly supported by the efficacy of aspirin and other antiplatelet drugs in preventing vascular events in the general population (Patrono et al 2004). Earlier studies had showed increased platelet aggregability in hypoxaemic COPD patients (Cordova et al 1985;

Table I Mechanisms of systemic inflammation in COPD

\begin{tabular}{lll}
\hline References & Type of study & Main evidence \\
\hline Pasceri et al 2000 & Basic research & $\begin{array}{l}\text { CPR upregulates the production of pro-inflammatory cytokines and tissue factor by monocytes. } \\
\text { It increases the uptake of LDL by macrophages with foam cells formation and directly induces } \\
\text { expression of adhesion molecules by human endothelial cells. } \\
\text { CRP is increased in COPD. }\end{array}$ \\
Sin et al 2003 & $\begin{array}{l}\text { Population-based } \\
\text { Population-based }\end{array}$ & $\begin{array}{l}\text { CRP is a prognostic factor in COPD. } \\
\text { Cross-sectional }\end{array}$ \\
Joppa et al 2006 & $\begin{array}{l}\text { Systemic inflammation might be pathogenetically related to pulmonary hypertension } \\
\text { complicating COPD. }\end{array}$ \\
Gan et al 2004 & Meta-analysis & Serum levels of TNF- $\alpha$, IL 6, IL 8, CRP, and fibrinogen are increased in COPD.
\end{tabular}

Abbreviations: COPD, chronic obstructive pulmonary disease; CRP, C-reactive protein; LDL, low-density lipoprotein; TNF- $\alpha$, tumor necrosis factor-alpha; IL 6, interleukin-6; IL 8, interleukin-8. 
Table 2 Mechanisms explaining the procoagulant status which characterizes COPD (see also Table 3)

\begin{tabular}{lll}
\hline References & Type of study & Main evidence \\
\hline Ogawa et al I990 & Basic research & $\begin{array}{l}\text { Hypoxia dynamically modulates endothelial function. The ensuing endothelial dysfunction } \\
\text { might promote microvascular lesions. } \\
\text { COPD patients have an ongoing prothrombotic state }\end{array}$ \\
$\begin{array}{l}\text { Alessandri et al 1994, } \\
\text { Ashitani et al 2002 and }\end{array}$ & $\begin{array}{l}\text { Case-control } \\
\text { Case-control } \\
\text { Case-control }\end{array}$ & $\begin{array}{l}\text { which might explain the high prevalence of } \\
\text { thrombosis in pulmonary vessels. }\end{array}$ \\
Wedzicha et al 2000 & Prospective & $\begin{array}{l}\text { Fibrinogen levels, which are basically higher than normal, further raise during } \\
\text { COPD exacerbation. }\end{array}$ \\
Danesh et al 1998 & Meta-analysis & High levels of serum fibrinogen reliably predicts cardiovascular events \\
\end{tabular}

Abbreviation: COPD, chronic obstructive pulmonary disease.

Wedzicha et al 1991). More recently, platelet aggregation has been studied in vivo by measuring 11-dehydro-thromboxane $\mathrm{B}_{2}\left(11-\mathrm{d}-\mathrm{TxB}_{2}\right.$ ), the urinary metabolites of $\mathrm{TxA}_{2}$ (Patrono et al 1995). This eicosanoid is generated by activated platelets through the enzyme cyclooxygenase- 1 , which is specifically inhibited by aspirin. Once released, $\mathrm{TxA}_{2}$ amplifies platelet aggregation and stimulates smooth muscle constriction and proliferation (Rolin et al 2006). TxA 2 is also a strong constrictor of bronchial smooth muscle cells and has been involved in the pathogenesis of asthma (Tamaoki et al 2000). The measurement of urinary 11-d-TxA directly reflects biosynthesis and is therefore a measure of platelet function (Patrono et al 1995). High excretory values identify patients at increased risk of myocardial infarction and cardiovascular death (Eikelboom et al 2002). Importantly, urinary 11-d- $\mathrm{TxB}_{2}$ values are significantly greater in patients with stable COPD than in control subjects, irrespective of smoking status, inversely correlated with arterial oxygen tension and are significantly lowered by short - term oxygen supplementation (Davì et al 1997). These data suggest a link between hypoxia and platelet activation likely because hypoxia induces metabolic changes on the platelet membrane, leading to increased activation of cyclooxygenase-1 with thromboxane formation (Ponicke et al 1987). In addition, platelet stimulation may result from clotting activation with thrombin generation, that, in turn, is well known to enhance platelet thromboxane biosynthesis (Patrono 1990).

\section{Oxidative stress (Table 4)}

The development of COPD is associated with oxidative stress and reduced antioxidant properties (Boots et al 2003). Hydrogen peroxide $\left(\mathrm{H}_{2} \mathrm{O}_{2}\right)$ in exhaled breath condensate is a marker of oxidative stress in the lungs and have been found to be elevated in COPD patients irrespective of smoking status (Dekhuijzen et al 1996; Nowak et al 1999), as well as in smokers without the disease (Nowak et al 2001). Oxidative stress can promote the peroxidation of polyunsaturated fatty acids. Thiobarbituric acid-reacting substances represent a measure of such a lipid peroxidation and are increased in exhaled breath condensate of patients with COPD (Nowak et al 1999).

Pulmonary oxidative stress "spreads out" to the circulation and becomes a systemic alteration (Boots et al 2003). F2-isoprostanes are stable products of peroxidation of arachidonic acid (Delanty et al 1996). The assay of F2-isoprostanes in the urine is a reliable measure of in vivo, systemic oxidative stress and, more importantly, it is a marker of LDL oxidation (Devaraj et al 2001), that, in turn, is a key event in the pathogenesis of atherosclerosis (Berliner and Heinecke 1996; Patrono et al 2004). Independently of current smoking, the excretion of F2-isoprostane increases significantly in COPD and peaks during exacerbations (Praticò et al 1998). This should suggest a LDL oxidative susceptibility in COPD, an abnormality potentially contributing to plaque formation.

Table 3 Epidemiological evidence and mechanisms of platelet hyperaggregability in COPD

\begin{tabular}{|c|c|c|}
\hline References & Type of study & Main evidence \\
\hline Ponicke et al 1987 & Basic research & $\begin{array}{l}\text { Hypoxia induces metabolic changes on the platelet membrane, leading to increased } \\
\text { activation of cyclooxygenase-I with thromboxane formation. }\end{array}$ \\
\hline Davì et al 1997 & Case-control & $\begin{array}{l}\text { Thromboxane excretion is increased in COPD, inversely correlates with oxygen tension } \\
\text { and is significantly lowered by short-term oxygen supplementation. }\end{array}$ \\
\hline Cordova et al 1985; & Case-control & Increased platelet aggregability in hypoxemic COPD patients. \\
\hline
\end{tabular}

Abbreviation: COPD, chronic obstructive pulmonary disease. 
Table 4 Potential mechanisms of oxidative stress in COPD

\begin{tabular}{|c|c|c|}
\hline References & Type of study & Main evidence \\
\hline Devaraj et al $200 \mathrm{I}$ & Basic research & $\begin{array}{l}\text { The assay of prostaglandin-like compounds in the urine is a reliable measure of in vivo oxidative } \\
\text { stress and represents a marker of LDL oxidation. }\end{array}$ \\
\hline Praticò et al 1998 & Case-control & $\begin{array}{l}\text { Independently of current smoking, the excretion of F2-isoprostane is increased in COPD } \\
\text { and peaks during exacerbations. }\end{array}$ \\
\hline
\end{tabular}

Abbreviations: LDL, low-density lipoprotein; COPD, chronic obstructive pulmonary disease.

\section{Lipid status and metabolic risk in COPD (Table 5)}

The increased vascular risk in COPD cannot be attributed to an atherogenic lipid pattern. In COPD patients, lipid levels are comparable with those measured in healthy subjects, with values of lipoprotein(a) and of APO B-100 being even significantly lower (Basili et al 1999).

The relation between diabetes mellitus, one of the leading atherothrombotic factors, and COPD is unclear. There are data supporting the notion that the lung is a target organ in diabetes, but abnormalities mostly include alveolar microangiopathy with impaired diffusion capacity (Hsia and Raskin 2005) and a restrictive ventilatory dysfunction (Lawlor et al 2004). Results of prospective observations in COPD patients are confounding. In a study, COPD was a risk factor for the onset of type 2 diabetes mellitus, but spirometric diagnostic data were not reported (Rana et al 2004). In another study, an obstructive pattern was not associated with the development of diabetes, that, conversely, was significantly increased in subjects with a restrictive ventilatory pattern (Ford and Mannino 2004). Accordingly, metabolic syndrome and insulin-resistance were very frequent in nondiabetic subjects with restrictive dysfunction, but not in COPD patients (Fimognari et al 2007).

\section{Neurohumoral activation}

There are convincing data demonstrating a COPD-related neurohumoral activation, including sympathetic overactivity, increased release of catecholamines and decreased vagal tone (Andreas et al 2005). This alteration is evident also after interruption of medications for COPD (Scalvini et al 1999) and is supposed to contribute to a generic cardiovascular and systemic risk in COPD (arrhythmias, cachexia, muscle wasting with fatigue) (Andreas et al 2005). The specific impact of neurohumoral activation on the atherothrombotic status of COPD, however, is unclear.

Animal models showed that sympathetic activation can promote systemic inflammation (Woiciechowsky et al 1998; Borovikova et al 2000; Li et al 2004). Theoretically, the neurohumoral activation occurring in COPD may thus favour atherothrombosis by stimulating systemic and vascular inflammation, but this potential causative association needs to be proven in patients with COPD.

Another mechanism by which the sympathetic activation may promote atherothrombosis in COPD is platelet activation. It is well known that the catecholamines released during acute stress may directly activate platelets (Hjemdahl et al 1991, 1994; Larsson et al 1994), but there are no data to demonstrate that this may also take place during chronic neurohumoral activation, like that complicating COPD (Fimognari et al 1996). In conclusion, the notion that the neurohumoral activation contributes to the COPD-related platelet hyperfunction is still highly speculative.

\section{Potential therapies (Table 6)}

The role of systemic inflammation in precipitating vascular events in COPD is strongly supported by accumulating data showing the potential benefits of inhaled corticosteroids. These drugs, commonly used to attenuate lung inflammation, have been demonstrated to reduce plasma CRP levels in stable COPD, suggesting a "cooling" effect also on systemic inflammation (Sin et al 2004; Pinto-Plata et al 2006). In a

Table 5 Lipid status and metabolic risk in COPD

\begin{tabular}{lll}
\hline References & Type of study & Main evidence \\
\hline Basili et al 1999 & Case-control & COPD patients and healthy subjects have comparable lipid levels. \\
Rana et al 2004 & Prospective & COPD might be a risk factor for incident type 2 diabetes mellitus. \\
Ford et al 2004 & Prospective & Restrictive, but not obstructive, subjects are at increased risk of developing type 2 diabetes mellitus. \\
Fimognari et al 2007 & Population-based & Metabolic syndrome and insulin-resistance are highly prevalent in nondiabetic subjects \\
& & with restrictive dysfunction, but not in COPD patients. \\
\hline
\end{tabular}

Abbreviation: COPD, chronic obstructive pulmonary disease. 
recent meta-analysis of randomized controlled trials (RCTs), the mortality of COPD patients on inhaled corticosteroids was $27 \%$ lower than that reported in the placebo group (adjusted hazard ratio, 0.73; 95\% confidence interval, 0.55-0.96) ( $\mathrm{Sin}$ et al 2005a). Of note, this is the same mortality reduction obtained by a 3-year therapy with simvastatin in the Scandinavian Simvastatin Survival Study (Scandinavian Simvastatin Survival Study Group 1994). Because the trials included in the meta-analysis were not planned to test the effect of inhaled steroids on survival, the result needs to be confirmed in RCTs specifically designed for this aim. However, the improved survival may be due to a reduction in cardiovascular deaths, in turn determined by the effect of inhaled corticosteroids on vascular plaque inflammation. This intriguing hypothesis is suggested by some important observational studies. Huiart and collegues (2005) found a 18\% nonsignificant reduction of myocardial infarctions amongst users of inhaled corticosteroids, but in a subgroup of patients taking 50-200 $\mu \mathrm{g} /$ day of steroids the risk reduction increased to $32 \%(p<0.05)$. A recent study, while confirming improved survival in corticosteroid users (Macie et al 2006), found that this benefit largely derived from a $38 \%$ reduction in cardiovascular mortality, while the reduction in respiratory deaths was nonsignificant. Recently, the EUROSCOP (European Respiratory Society Study on Chronic Pulmonary Disease) trial reported a $40 \%$ reduction in the rate of coronary artery disease events in patients taking inhaled corticosteroids compared to the placebo group (Lofdahl et al 2005).

Very recently, the effect on mortality of inhaled corticosteroids has been questioned by the results of an important RCT, the TORCH (Toward a Revolution in COPD Health) study (Calverley et al 2007). The mortality rate at 3 years in the fluticasone group (16\%) was comparable to that observed in the placebo group (15.2\%). In patients treated with the combination therapy of fluticasone plus the long-acting $\beta_{2}$-agonist salmeterol (mortality rate: $12.6 \%$ ) there was an interesting $17.5 \%$ reduction in the risk of death compared with placebo, with a nonsignificant difference $(p=0.052)$. The impact of these drugs on cardiovascular mortality only was not reported. It is possible that the combination therapy does improve survival in COPD patients and that this study was underpowered to detect this effect. In addition, because $\beta_{2}$-agonists activate glucocorticoid receptors in the lung (Eickelberg et al 1999), the association with $\beta_{2}$-agonists may be crucial to highlight any effect of inhaled corticosteroids on mortality.

The only treatment improving survival in COPD is longterm oxygen therapy in hypoxemic patients (Afessa et al 2002). Oxygen therapy may prevent the hypoxia-induced platelet activation and blood clotting, and part of its clinical benefit may come from a reduction of atherothrombotic fatal events by these effects. Furthermore, oxygen supplementation prevents exercise-induced oxidative stress in normoxemic, muscle-wasted patients with COPD (van Helvoort et al 2006). However, short-term oxygen supplementation has also been reported to promote oxidative stress and airway inflammation (Carpagnano et al 2004).

\section{Conclusion}

COPD is now recognized as a systemic inflammatory disease that may adversely affect the arterial district, predisposing patients to an increased risk of atherosclerotic plaque formation and rupture. Systemic inflammation plays a leading role in this process, but other mechanisms, such as platelet activation, coagulation and oxidative stress, can promote atherosclerosis in COPD. Research is needed to further

Table 6 Potential therapies of systemic inflammation in COPD

\begin{tabular}{|c|c|c|}
\hline References & Type of study & Main evidence \\
\hline Sin et al 2004 & Randomized placebo-control & Inhaled corticosteroids reduce plasma CRP levels in stable COPD. \\
\hline Pinto-Plata et al 2006 & Cross-sectional analysis & "Cooling" effect of inhaled corticosteroids on systemic inflammation. \\
\hline Huiart et al 2005 & Observational & $\begin{array}{l}\text { COPD patients taking } 50-200 \mu \mathrm{g} / \text { day of inhaled steroids } \\
\text { have a } 32 \% \text { fall of the risk of myocardial infarction. }\end{array}$ \\
\hline Macie et al 2006 & Observational & $\begin{array}{l}\text { Reduction in cardiovascular mortality by } 38 \% \text { accounts for the improved } \\
\text { survival associated with chronic use of inhaled steroids. }\end{array}$ \\
\hline Sin et al 2005 & Pooled analysis from 7 RCT's & $27 \%$ mortality decrease in COPD patients taking inhaled corticosteroids. \\
\hline Lofdahl et al 2005 & $R C T$ & $\begin{array}{l}40 \% \text { reduction in the rate of coronary artery disease events after therapy } \\
\text { with inhaled budesonide compared with the placebo group. }\end{array}$ \\
\hline Cochrane 2005 & Meta-analysis & $\begin{array}{l}\text { The only evidence-based treatment improving survival is long-term } \\
\text { oxygen therapy in hypoxemic patients. } \\
\text { To note: Oxygen has antioxidant and anti-inflammatory } \\
\text { activity in hypoxemic COPD. }\end{array}$ \\
\hline
\end{tabular}

Abbreviations: CRP, C-reactive protein; COPD, chronic obstructive pulmonary disease; RCT, randomized controlled trials. 
clarify mechanisms of atherothrombosis, as well as to identify therapeutic and preventive strategies. Current evidence is consistent with an optimal care of bronchial inflammation likely translating in some reduction of atherothrombotic risk. However, the very early development of the pro-atherothrombotic status in the course of COPD suggests that researchers should think of COPD as of a systemic disease from its onset. Accordingly, patients should receive advice about nonrespiratory effects of COPD. This communication strategy might improve the awareness of the disease status and of the need of halting its progression by the most important preventive measure: smoking cessation.

Eventually, the evidence of systemic effects of COPD should induce pneumologists to have a multidisciplinary and multidimensional approach to the disease by involving various specialists. The relatively poor progress in the treatment of COPD in the second half of the last century, when compared with therapy of other chronic diseases, likely reflects the purely respiratory-centered, then scotomic, view of the disease.

\section{References}

Afessa B, Morales IJ, Scanlon PD, et al. 2002. Prognostic factors, clinical course, and hospital outcome of patients with chronic obstructive pulmonary disease admitted to an intensive care unit for acute respiratory failure. Crit Care Med, 30:1610-15.

Alessandri C, Basili S, Violi F, et al. 1994. Hypercoagulability state in patients with chronic obstructive pulmonary disease. Chronic Obstructive Bronchitis and Haemostasis Group. Thromb Haemost, 72:343-6.

Andreas S, Anker SD, Scanlon PD, et al. 2005. Neurohumoral activation as a link to systemic manifestations of chronic lung disease. Chest, 128:3618-24.

Ashitani J, Mukae H, Arimura Y, et al. 2002. Elevated plasma procoagulant and fibrinolytic markers in patients with chronic obstructive pulmonary disease. Intern Med, 41:181-5.

Basili S, Ferroni P, Vieri M, et al. 1999. Lipoprotein(a) serum levels in patients affected by chronic obstructive pulmonary disease. Atherosclerosis, 147:249-52.

Berliner JA, Heinecke JW. 1996. The role of oxidized lipoproteins in atherogenesis. Free Radic Biol Med, 20:707-27.

Boots AW, Haenen GR, Bast A. 2003. Oxidant metabolism in chronic obstructive pulmonary disease. Eur Respir J Suppl, 46:14s-27s.

Borovikova LV, Ivanova S, Zhang M, et al. 2000. Vagus nerve stimulation attenuates the systemic inflammatory response to endotoxin. Nature, 405:458-62.

Calverley PM, Walker P. 2003. Chronic obstructive pulmonary disease. Lancet, 362:1053-61.

Calverley PM, Anderson JA, Celli B, et al; TORCH investigators. 2007. Salmeterol and fluticasone propionate and survival in chronic obstructive pulmonary disease. $N$ Engl $J$ Med, 356:775-89.

Carpagnano GE, Kharitonov SA, Foschino-Barbaro MP, et al. 2004. Supplementary oxygen in healthy subjects and those with COPD increases oxidative stress and airway inflammation. Thorax, 59:1016-19.

Cordova C, Musca A, Violi F, et al. 1985. Platelet hyperfunction in patients with chronic airways obstruction. Eur J Respir Dis, 66:9-12.

Danesh J, Collins R, Appleby P, et al. 1998. Association of fibrinogen, C-reactive protein, albumin, or leukocyte count with coronary heart disease: meta-analyses of prospective studies. JAMA, 279:1477-82.
Davì G, Basili S, Vieri M, et al. 1997. Enhanced thromboxane biosynthesis in patients with chronic obstructive pulmonary disease. The Chronic Obstructive Bronchitis and Haemostasis Study Group. Am J Respir Crit Care Med, 156:1794-9.

Dekhuijzen PN, Aben KK, Dekker I, et al. 1996. Increased exhalation of hydrogen peroxide in patients with stable and unstable chronic obstructive pulmonary disease. Am J Respir Crit Care Med, 154:813-16.

Delanty N, Reilly M, Pratico D, et al. 1996. 8-Epi PGF2 alpha: specific analysis of an isoeicosanoid as an index of oxidant stress in vivo. $\mathrm{BrJ}$ Clin Pharmacol, 42:15-19.

Devaraj S, Hirany SV, Burk RF, et al. 2001. Divergence between LDL oxidative susceptibility and urinary $\mathrm{F}(2)$-isoprostanes as measures of oxidative stress in type 2 diabetes. Clin Chem, 47:1974-9.

Eickelberg O, Roth M, Lorx R, et al. 1999. Ligand-independent activation of the glucocorticoid receptor by beta2-adrenergic receptor agonists in primary human lung fibroblasts and vascular smooth muscle cells. J Biol Chem, 274:1005-10.

Eikelboom JW, Hirsh J, Weitz JI, et al. 2002. Aspirin-resistant thromboxane biosynthesis and the risk of myocardial infarction, stroke, or cardiovascular death in patients at high risk for cardiovascular events. Circulation, 105:1650-5.

Engstrom G, Wollmer P, Hedblad B, et al. 2001. Occurrence and prognostic significance of ventricular arrhythmia is related to pulmonary function: a study from "men born in 1914," Malmo, Sweden. Circulation, 103:3086-91.

Esmon CT. 2000. Does inflammation contribute to thrombotic events? Haemostasis, 30(Suppl 2):34-40.

Fimognari FL, Pasqualetti P, Moro L, et al. 2007. The association between metabolic syndrome and restrictive ventilatory dysfunction in older persons. J Gerontol A Biol Sci Med, 62:760-5.

Fimognari FL, Piccirillo G, Lama J, et al. 1996. Associated daily biosynthesis of cortisol and thromboxane A2: a preliminary report. $J$ Lab Clin Med, 128:115-21.

Ford ES, Mannino DM. 2004. Prospective association between lung function and the incidence of diabetes: findings from the National Health and Nutrition Examination Survey Epidemiologic Follow-up Study. Diabetes Care, 27:2966-70.

Gan WQ, Man SF, Senthilselvan A, et al. 2004. Association between chronic obstructive pulmonary disease and systemic inflammation: a systematic review and a meta-analysis. Thorax, 59:574-80.

Halbert RJ, Natoli JL, Gano A, et al. 2006. Global burden of COPD: systematic review and meta-analysis. Eur Respir J, 28:523-32.

Hansell AL, Walk JA, Soriano JB. 2003. What do chronic obstructive pulmonary disease patients die from? A multiple cause coding analysis. Eur Respir J, 22:809-14.

Hjemdahl P, Larsson PT, Wallen NH. 1991. Effects of stress and betablockade on platelet function. Circulation, 84:VI44-61.

Hjemdahl P, Chronos NA, Wilson DJ, et al. 1994. Epinephrine sensitizes human platelets in vivo and in vitro as studied by fibrinogen binding and P-selectin expression. Arterioscler Thromb, 14:77-84.

Hole DJ, Watt GC, Davey-Smith G, et al. 1996. Impaired lung function and mortality risk in men and women: findings from the Renfrew and Paisley prospective population study. BMJ, 313:711-15.

Hsia CC, Raskin P. 2005. The diabetic lung: relevance of alveolar microangiopathy for the use of inhaled insulin. Am J Med, 118:205-11.

Huiart L, Ernst P, Ranouil X, et al. 2005. Low-dose inhaled corticosteroids and the risk of acute myocardial infarction in COPD. Eur Respir J, 25:634-9.

Joppa P, Petrasova D, Stancak B, et al. 2006. Systemic inflammation in patients with COPD and pulmonary hypertension. Chest, 130:326-33.

Larsson PT, Wallen NH, Hjemdahl P. 1994. Norepinephrine-induced human platelet activation in vivo is only partly counteracted by aspirin. Circulation, 89:1951-7.

Lawlor DA, Ebrahim S, Smith GD. 2004. Associations of measures of lung function with insulin resistance and Type 2 diabetes: findings from the British Women's Heart and Health Study. Diabetologia, 47:195-203 
Li M, Zheng C, Sato T, et al. 2004. Vagal nerve stimulation markedly improves long-term survival after chronic heart failure in rats. Circulation, 109:120-4.

Libby P, Simon DI. 2001. Inflammation and thrombosis: the clot thickens. Circulation, 103:1718-20.

Lofdahl CG, Postma D, Pride N. 2005. Does inhaled budesonide protect against cardio-ischemic events in mild-moderate COPD: a post-hoc evaluation of the EUROSCOP Study [Abstract]. European Respiratory Society Conference, Copenhagen 2005.

Macie C, Wooldrage K, Manfreda J, et al. 2006. Inhaled corticosteroids and mortality in COPD. Chest, 130:640-6.

Man SF, Connett JE, Anthonisen NR, et al. 2006. C-reactive protein and mortality in mild to moderate chronic obstructive pulmonary disease. Thorax, 61:849-53.

Meier CR, Jick SS, Derby LE, et al. 1998. Acute respiratory-tract infections and risk of first-time acute myocardial infarction. Lancet, 351:1467-71.

Nowak D, Kasielski M, Antczak A, et al. 1999. Increased content of thiobarbituric acid-reactive substances and hydrogen peroxide in the expired breath condensate of patients with stable chronic obstructive pulmonary disease: no significant effect of cigarette smoking. Respir Med, 93:389-96.

Nowak D, Kalucka S, Bialasiewicz P, et al. 2001. Exhalation of $\mathrm{H}_{2} \mathrm{O}_{2}$ and thiobarbituric acid reactive substances (TBARs) by healthy subjects. Free Radic Biol Med, 30:178-86.

Ogawa S, Shreeniwas R, Brett J, et al. 1990. The effect of hypoxia on capillary endothelial cell function: modulation of barrier and coagulant function. Br J Haematol, 75:517-24.

Pasceri V, Willerson JT, Yeh ET. 2000. Direct proinflammatory effect of C-reactive protein on human endothelial cells. Circulation, 102:2165-8.

Patrono C. 1990. Thromboxane synthesis inhibitors and receptor antagonists. Thromb Res Suppl, 11:15-23.

Patrono C, Coller B, FitzGerald GA, et al. 2004. Platelet-active drugs: the relationships among dose, effectiveness, and side effects: the Seventh ACCP Conference on Antithrombotic and Thrombolytic Therapy. Chest, 126:234S-264S.

Patrono C, Patrignani P, Rocca B, et al. 1995. Characterization of biochemical and functional effects of antiplatelet drugs as a key to their clinical development. Thromb Haemost, 74:396-400.

Pinto-Plata VM, Mullerova H, Toso JF, et al. 2006. C-reactive protein in patients with COPD, control smokers and non-smokers. Thorax, 61:23-8.

Ponicke K, Sternitzky R, Mest HJ. 1987. Stimulation of aggregation and thromboxane A 2 formation of human platelets by hypoxia. Prostaglandins Leukot Med, 29:49-59.

Praticò D, Basili S, Vieri M, et al. 1998. Chronic obstructive pulmonary disease is associated with an increase in urinary levels of isoprostane F2alpha-III, an index of oxidant stress. Am J Respir Crit Care Med, 158:1709-14.

Rabinovich RA, Figueras M, Ardite E, et al. 2003. Increased tumour necrosis factor-alpha plasma levels during moderate-intensity exercise in COPD patients. Eur Respir J, 21:789-94.

Rana JS, Mittleman MA, Sheikh J, et al. 2004. Chronic obstructive pulmonary disease, asthma, and risk of type 2 diabetes in women. Diabetes Care, 27:2478-84.

Rolin S, Masereel B, Dogne JM. 2006. Prostanoids as pharmacological targets in COPD and asthma. Eur J Pharmacol, 533:89-100.
Russo A, De Luca M, Vigna C, et al. 1999. Central pulmonary artery lesions in chronic obstructive pulmonary disease: A transesophageal echocardiography study. Circulation, 100:1808-15.

Scandinavian Simvastatin Survival Study Group 1994. Randomised trial of cholesterol lowering in 4444 patients with coronary heart disease: the Scandinavian Simvastatin Survival Study (4S). Lancet, 344:1383-9.

Scalvini S, Porta R, Zanelli E, et al. 1999. Effects of oxygen on autonomic nervous system dysfunction in patients with chronic obstructive pulmonary disease. Eur Respir J, 13:119-24.

Sin DD, Lacy P, York E, et al. 2004. Effects of fluticasone on systemic markers of inflammation in chronic obstructive pulmonary disease. Am J Respir Crit Care Med, 170:760-5.

Sin DD, Wu L, Anderson JA, et al. 2005a. Inhaled corticosteroids and mortality in chronic obstructive pulmonary disease. Thorax, 60:992-7.

Sin DD, Wu L, Man SF. 2005b. The relationship between reduced lung function and cardiovascular mortality: a population-based study and a systematic review of the literature. Chest, 127:1952-9.

Takabatake N, Nakamura H, Abe S, et al. 2000. The relationship between chronic hypoxemia and activation of the tumor necrosis factor-alpha system in patients with chronic obstructive pulmonary disease. Am J Respir Crit Care Med, 161:1179-84.

Tamaoki J, Kondo M, Nakata J, et al. 2000. Effect of a thromboxane A(2) antagonist on sputum production and its physicochemical properties in patients with mild to moderate asthma. Chest, 118:73-9.

Truelsen T, Prescott E, Lange P, et al. 2001. Lung function and risk of fatal and non-fatal stroke. The Copenhagen City Heart Study. Int J Epidemiol, 30:145-51.

van Helvoort HA, Heijdra YF, Heunks LM, et al. 2006. Supplemental oxygen prevents exercise-induced oxidative stress in muscle-wasted patients with chronic obstructive pulmonary disease. Am J Respir Crit Care Med, 173:1122-9.

Vestbo J. 2004. The TORCH (towards a revolution in COPD health) survival study protocol. Eur Respir J, 24:206-10.

Wedzicha JA, Seemungal TA, MacCallum PK, et al. 2000. Acute exacerbations of chronic obstructive pulmonary disease are accompanied by elevations of plasma fibrinogen and serum IL-6 levels. Thromb Haemost, 84:210-15.

Wedzicha JA, Syndercombe-Court, Tan KC. 1991. Increased platelet aggregate formation in patients with chronic airflow obstruction and hypoxaemia. Thorax, 46:504-7.

Weitzenblum E, Hirth C, Ducolone A, et al. 1981. Prognostic value of pulmonary artery pressure in chronic obstructive pulmonary disease. Thorax, 36:752-8.

Woiciechowsky C, Asadullah K, Nestler D, et al. 1998. Sympathetic activation triggers systemic interleukin-10 release in immunodepression induced by brain injury. Nat Med, 4:808-13.

Xie M, Wang Z. 1998. [Prethrombotic state in patients with chronic obstructive pulmonary disease and treatment with heparin]. Hua Xi Yi Ke Da Xue Xue Bao, 29:411-14.

Zoppini G, Targher G, Zamboni C, et al. 2006. Effects of moderate-intensity exercise training on plasma biomarkers of inflammation and endothelial dysfunction in older patients with type 2 diabetes. Nutr Metab Cardiovasc Dis, 16:543-9.

Zureik M, Benetos A, Neukirch C, et al. 2001. Reduced pulmonary function is associated with central arterial stiffness in men. Am J Respir Crit Care Med, 164:2181-5. 